Article

\title{
The Arabidopsis GPR1 Gene Negatively Affects Pollen Germination, Pollen Tube Growth, and Gametophyte Senescence
}

\author{
Xiao Yang, Qinying Zhang, Kun Zhao, Qiong Luo, Shuguang Bao, Huabin Liu \\ and Shuzhen Men * \\ Department of Plant Biology and Ecology, College of Life Sciences, Nankai University, Tianjin 300071, China; \\ yang_xiao2016@163.com (X.Y.); zhangqinying@mail.nankai.edu.cn (Q.Z.); aslan1102@163.com (K.Z.); \\ qiongluo2016@mail.nankai.edu.cn (Q.L.); shuguang@mail.nankai.edu.cn (S.B.); \\ liuhuabin@mail.nankai.edu.cn (H.L.) \\ * Correspondence: shuzhenmen@nankai.edu.cn; Tel.: +86-22-2350-0856
}

Received: 13 May 2017; Accepted: 13 June 2017; Published: 21 June 2017

\begin{abstract}
Genes essential for gametophyte development and fertilization have been identified and studied in detail; however, genes that fine-tune these processes are largely unknown. Here, we characterized an unknown Arabidopsis gene, GTP-BINDING PROTEIN RELATED1 (GPR1). GPR1 is specifically expressed in ovule, pollen, and pollen tube. Enhanced green fluorescent protein-tagged GPR1 localizes to both nucleus and cytoplasm, and it also presents in punctate and ring-like structures. gpr1 mutants exhibit no defect in gametogenesis and seed setting, except that their pollen grains are pale in color. Scanning electron microscopy analyses revealed a normal patterned but thinner exine on gpr1 pollen surface. This may explain why gpr1 pollen grains are pale. We next examined whether GPR1 mutation affects post gametogenesis processes including pollen germination, pollen tube growth, and ovule senescence. We found that gpr1 pollen grains germinated earlier, and their pollen tubes elongated faster. Emasculation assay revealed that unfertilized gpr1 pistil expressed the senescence marker $P_{B F N 1}$ :GUS (GUS: a reporter gene that encodes $\beta$-glucuronidase) one-day earlier than the wild type pistil. Consistently, ovules and pollen grains of gpr1 mutants showed lower viability than those of the wild type at 4 to 5 days post anthesis. Together, these data suggest that GPR1 functions as a negative regulator of pollen germination, pollen tube growth, and gametophyte senescence to fine-tune the fertilization process.
\end{abstract}

Keywords: pollen germination; pollen tube; gametophyte; senescence; expression; pollen exine

\section{Introduction}

Successful sexual reproduction of flowering plants depends on pollination, pollen tube growth, and double fertilization. Mature pollen, in a partially dehydrated and dormant state, release from anther to adhere to the female stigmatic tissue via wind, animal pollinators or direct contact. If the pollen grain is compatible with the stigma, it will soon hydrate and start to germinate. Previous studies have revealed that pollen germination is a highly controlled process [1-3].

In Arabidopsis, only a few genes have been reported to inhibit pollen germination. The raring-to-go ( rtg) mutant was identified for precocious pollen germination within the anther [4]. However, the RTG gene has not been cloned and the molecular mechanism involved remains unknown. Precocious pollen germination was also observed in mutants that genetically altered callose synthesis, including CALLOSE SYNTHASE9 gene knockout mutant cs9 and CALLOSE SYNTHASE5 over-expressing line CALS5. Both of them displayed abnormal callose deposition during microsporogenesis, and their pollen grains germinated precociously at bicellular stage [5]. In addition, precocious pollen germination 
also results from a disruption of inositol polyphosphate 5-phosphatase 12 (5PT12), which controls the cellular Ins $(1,4,5) P 3 / \mathrm{Ca}^{2+}$ levels. The knockout mutant $5 p t 12$ displays normal pollen development and pollen dehydration, revealing that independent of dehydration, the $\operatorname{Ins}(1,4,5) \mathrm{P3} / \mathrm{Ca}^{2+}$ levels is crucial for maintaining pollen dormancy [6]. Very recently, a protein that contains seven WD40 repeats was identified to inhibit pollen germination in moist environments [7]. This protein was named JINGUBANG (JGB). Further analysis revealed that JGB interacts with the transcription factor TCP4 to control pollen jasmonic acid (JA) synthesis [7].

As pollen tube grows, female tissue produces signals that direct the pollen tube to the embryo sac for fertilization [8-11]. Proper elongation of the growing tube is essential for fertilization. Pollen tube growth is driven by two major biochemical mechanisms: a calcium gradient at the growing tip and the highly dynamic subapical actin cytoskeleton [12-14]. Pollen tubes exhibit a steep, tip-focused cytoplasmic $\mathrm{Ca}^{2+}$ gradient. In the tip of growing pollen tube, free $\mathrm{Ca}^{2+}$ concentration is approximately several micromolar, whereas in the shank of the tube its concentration is approximately 100 nanomolar [15]. As a central regulator of pollen germination and tube growth, calcium also regulates the cytoskeleton via actin binding proteins [16-18]. After fertilization, the pistil undergoes growth and differentiation to become a fruit, whereas if ovules are not fertilized within anthesis, the pistil will initiate senescence process $[19,20]$. Therefore, ovule lifespan is an important factor in determining the ability to set fruits and produce seeds. However, the post-anthesis development of the unfertilized ovules has received little attention.

In order to isolate sperm-cell-expressed transcripts, $\mathrm{Xu}$ et al. isolated and purified tobacco sperm cells from in vitro grown pollen tubes, then extracted mRNA from these sperm cells to construct a cDNA library. By screening of this library they identified two sperm-cell-expressed transcripts, and named them NtS1 and NtS2. Further analysis showed that NtS1 and NtS2 transcription levels were higher in the pollen than in the sperm cell, suggesting that both genes were not sperm-cell-specific [21]. $\mathrm{NtS1}$ codes for a protein with a polygalacturonase active site. The putative NtS2 protein shares $65 \%$ amino acid sequence similarity to an unknown Arabidopsis protein encoded by the At3g23860 gene [21].

In this study, we characterized the unknown Arabidopsis At3g23860 gene. In Arabidopsis TAIR10, this gene was annotated to encode a GTP-binding related protein (http://www.arabidopsis.org). Therefore, we named it as GTP-BINDING PROTEIN RELATED1 (GPR1). GPR1 encodes a putative protein of 231 amino acids. BLAST searches identified no recognizable domain in GPR1. We analyzed the expression pattern of the GPR1 gene using reverse transcription (RT)-polymerase chain reaction (PCR) and GPR1 promoter:GUS (ProGPR1:GUS) transgenic plants, and found that GPR1 gene was specifically expressed in male and female gametophytes and pollen tubes. We obtained two insertion mutant alleles of the GPR1 gene, named as gpr1-1 (SALKseq_034266, in Col background) and gpr1-2 (CSHL_GT24095, in Ler background). Although gpr1 mutants were not defective in gametogenesis and fertilization, their pollen grains displayed pale yellow color compared with those of wild type. Scanning electron microscopy examination showed that gpr 1 mutant pollen grains had a thinner exine surface compared with those of wild type, suggesting that GPR1 plays a role in pollen coat formation. We also performed in vitro and in vivo pollen germination assay, and found that pollen grains of the gpr1 mutants germinated earlier and their pollen tubes elongated faster. Finally, we performed emasculation and hand pollination analysis, and demonstrated that loss of GPR1 function resulted in early senescence of ovules and pollen grains.

\section{Results}

\subsection{GPR1 Is Specifically Expressed in Ovule, Pollen and Pollen Tube}

GPR1 shares high similarity to the tobacco sperm-cell-expressed transcript NtS2. Therefore, we investigated whether GPR1 gene is also specifically expressed in pollen grains. RT-PCR analysis revealed that GPR1 transcript was strongly accumulated in flower buds, flowers, and young siliques, 
but was barely detectable in seedlings, rosette and cauline leaves, and stems (Supplemental Figure S1A). Our results are very similar to the publicly available expression profile of the GPR1 gene based on RNA-sequencing (RNA-seq) analysis (Supplemental Figure S1B). To investigate the expression of GPR1 in detail, we generated ProGPR1:GUS transgenic lines expressing GUS reporter gene under control of the GPR1 promoter. Consistent with the above results, GUS staining was only detected in flowers at developmental stages 9 to 13 and one day post anthesis, and the GUS signal was restricted to anthers and ovules (Figure 1A,B; Supplemental Figure S2). In anthers, GUS signal was specifically detected in tapetum and developing pollen (Figure $1 \mathrm{C}, \mathrm{D}$ ). In vitro and in vivo pollen germination analysis showed that ProGPR1:GUS was also expressed in pollen tubes at high levels (Figure 1E,F). In ovules, ProGPR1:GUS was expressed specifically in the embryo sac through stage FG3 to the mature stage of FG7, and its expression was still detectable one day post anthesis (Figure 2).

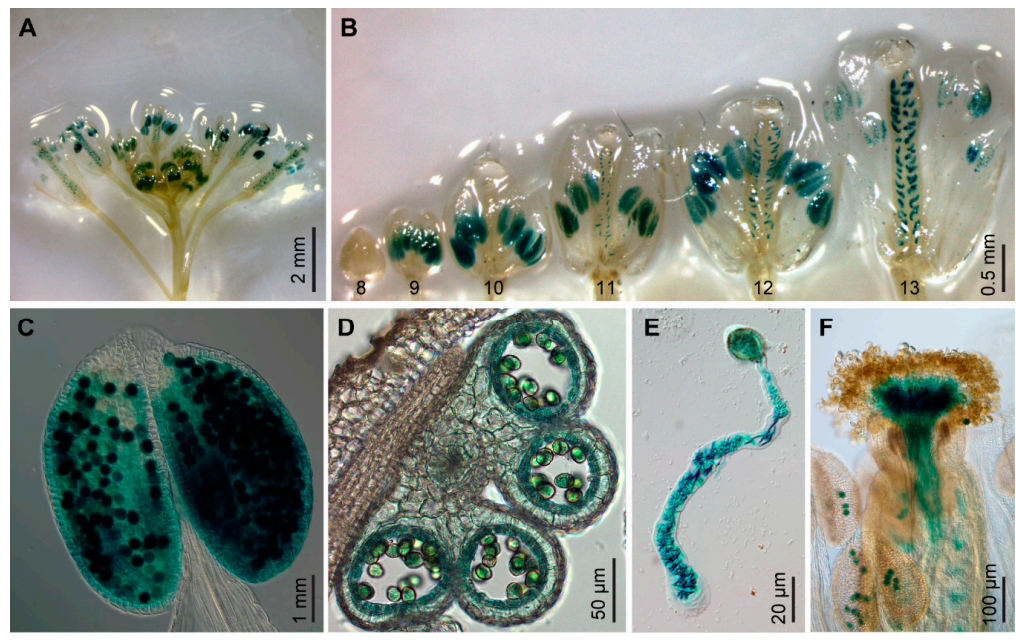

Figure 1. GPR1 promoter:GUS (ProGPR1:GUS) is specifically expressed in anthers, ovules and pollen tubes. (A) Expression of ProGPR1:GUS in inflorescence. (B) Flowers at different developmental stages, showing GUS staining in anthers from stage 9 to 13 , and in ovules from stage 11 to 13 . (C) Anther at stage 12, showing GUS signals in pollen grains. (D) Cross section of an anther at stage 11, showing GUS signals in tapetum and pollen grains. (E,F) Pollen grain germinated in vitro (E) and on pistil (F). Note GUS signals in pollen tube.

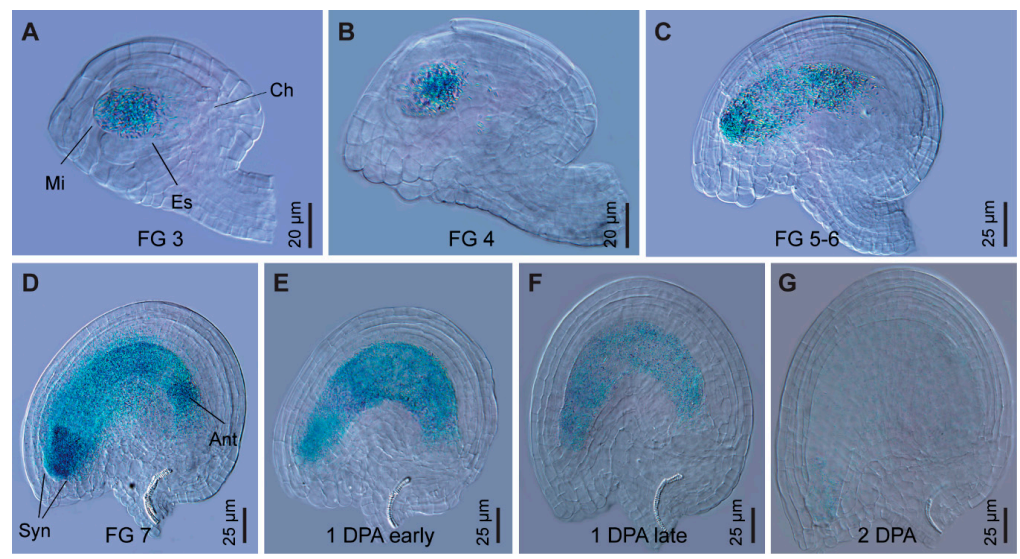

Figure 2. ProGPR1:GUS is specifically expressed in embryo sac during female gametophyte development. (A-D) GUS staining in ovules of ProGPR1:GUS plants at female gametophyte (FG) developmental stages FG 3 (A), FG 4 (B), FG 5-6 (C) and FG 7 (D). Mi, micropylar pole; Ch, chalazal pole; Es, embryo sac; Syn, synergids; Ant, antipodals. (E,F) Seeds at 1 day post anthesis (DPA). (G) Seed at 2 DPA. 


\subsection{GPR1 Protein Localizes to Nucleus and Cytoplasm}

To explore the subcellular localization of GPR1 protein, we generated transgenic Arabidopsis plants expressing either a C-terminal fusion of GPR1 and ENHANCED GREEN FLUORESCENT PROTEIN (EGFP) under control of the GPR1 promoter (ProGPR1:GPR1-EGFP), or a N-terminal fusion of GPR1 and EGFP under control of the 35S promoter (Pro35S:EGFP-GPR1). Consistent with the ProGPR1: GUS expression patterns, ProGPR1:GPR1-EGFP was only expressed in tapetum, developing pollen and ovule (Supplemental Figure S3; Figures 3 and 4). During pollen development, GPR1-EGFP signal was undetectable in pollen mother cell (Figure 3A), then was detected in nucleus and cytoplasm of tetrad, microspore, polarized microspore, and bicellular pollen (Figure 3B-E; Supplemental Figure S3). Furthermore, in bicellular pollen, GPR1-EGFP signal was strong in the vegetative cell nucleus but was undetectable in the germ cell nuclei (Figure 3E; Supplemental Figure S3). In mature pollen, the GPR1-EGFP signal was decreased to below detectable level (Figure 3F). In in vitro germinated pollen tubes, GPR1-EGFP signal was also undetectable (Data not shown). ProGPR1: GUS showed strong expression in mature pollen and pollen tube. Therefore, to determine the localization of GPR1-EGFP in mature pollen and pollen tube, we generated transgenic lines expressing ProLAT52:GPR1-EGFP (ProLAT52 is a strong pollen-specific promoter). In mature pollen, ProLAT52:GPR1-EGFP signal was detected in nucleus and cytoplasm of the vegetative cell, but was undetectable in the germ cell nuclei (Figure 3G-I). This is consistent with the expression pattern of ProGPR1:GPR1-EGFP in bicellular pollen (Supplemental Figure S3B). In pollen tube, GPR1-EGFP was also only detected in the vegetative nucleus and cytoplasm (Figure 3J-L). Furthermore, the GPR1-EGFP localized to some punctate and ring-like structures in the cytosol of the vegetative cell (Figure 3G,J). During ovule development, GPR1-EGFP signal was undetectable at developmental stage 2-III (Figure 4A), then was first detected in megaspore mother cell at stage 3-I (Figure 4B), and maintains in functional megaspore, coenocytic female gametophyte and mature embryo sac, and also resided in nucleus and cytoplasm (Figure 4C-G). GPR1-EGFP labeled punctate structures was also observed in cytoplasm of female gametophyte (Supplemental Figure S4). We also examined the EGFP-GPR1 signals in root tips of the Pro35S: EGFP-GPR1 transgenic plants. We found that EGFP-GPR1 also localized to both nucleus and cytoplasm of root cells, and also resided in punctate and ring-like structures (Supplemental Figure S5). The identity of these structures remains to be elucidated.

\subsection{GPR1 Is Not the Ortholog of the Tobacco NtS2}

GPR1 was reported to be the orthologous of the tobacco sperm-cell-expressed protein NtS2 [21]. However, unlike NtS2, GPR1 was not detectable in sperm cell nuclei (Figure 3E,G-L; Supplemental Figure S3B). Therefore, we did amino acid sequence alignment of NtS2 and GPR1. To our surprise, these two proteins only share 20\% sequence similarity (Supplemental Figure S6A). We then searched the Arabidopsis database using NtS2 amino acid sequence, and found that it shares $64 \%$ similarity with the putative protein At3g23870 (Supplemental Figure S6B). 

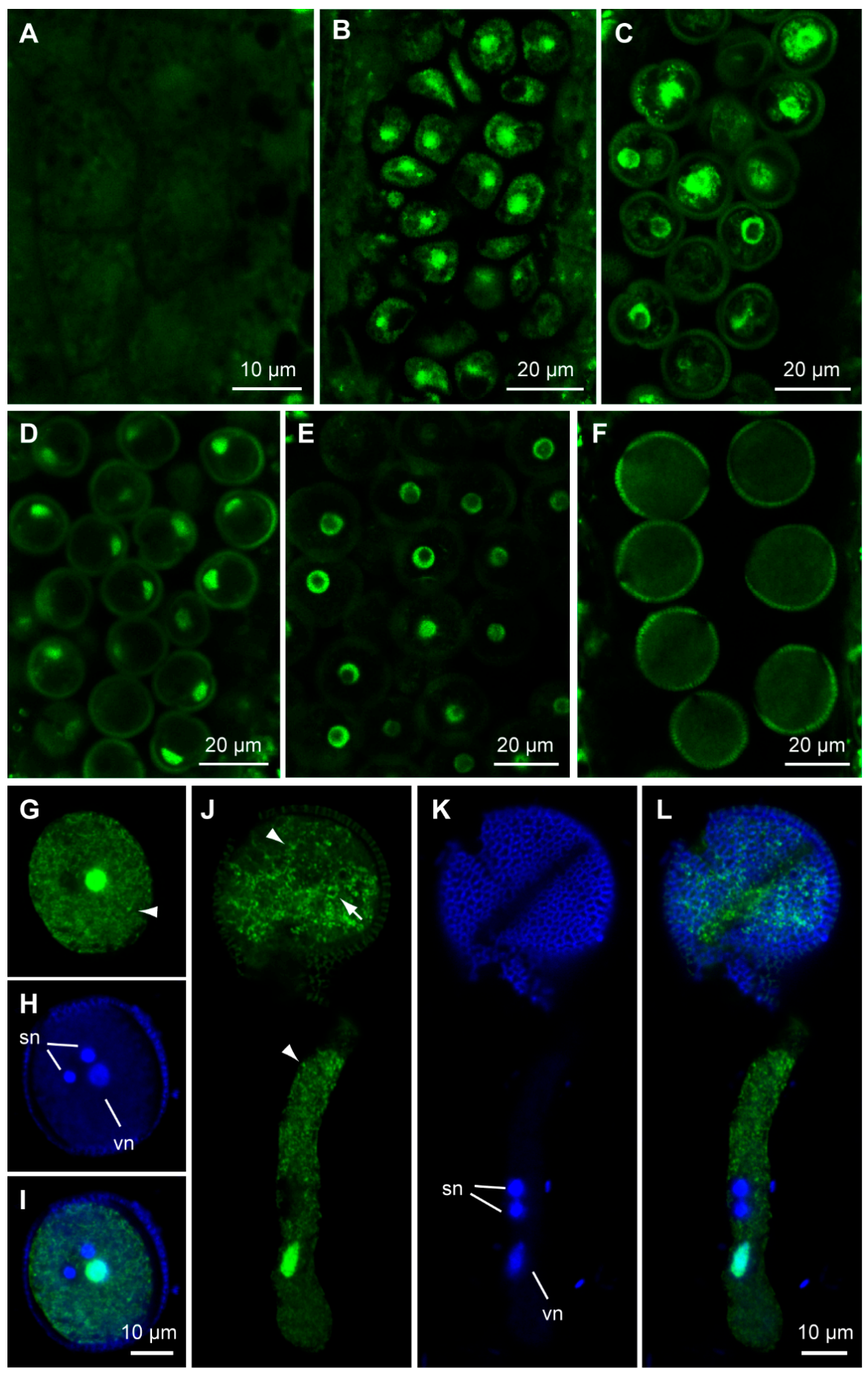

Figure 3. Expression patterns of ProGPR1:GPR1-EGFP and ProLAT52:GPR1-EGFP during microsporogenesis. (A-F) ProGPR1:GPR1-EGFP expression during microsporogenesis. There is no detectable GPR1-EGFP fluorescence in pollen mother cells (A); then strong GPR1-EGFP signals were detected in nucleus and cytoplasm of the tetrad (B), microspore (C), polarized microspore (D), and bicellular pollen (E); GPR1-EGFP signal was undetectable in mature pollen (F). (G-L) Co-staining of ProLAT52:GPR1-EGFP and DAPI in mature pollen (G-I) and pollen tube (J-L). (G,J) GPR1-EGFP signals; (H,K) DAPI stained nuclei; $(\mathbf{I}, \mathbf{L})$ merged images of $(\mathbf{G}, \mathbf{H})$ and $(\mathbf{J}, \mathbf{K})$. sn: sperm nucleus; vn: vegetative nucleus. Figure (G) to $(\mathbf{I})$ shares the same scale bar as shown in (I); Figure (J) to $(\mathbf{L})$ shares the same scale bar as shown in (L). Note GFP signal overlapped with DAPI only in vegetative nucleus. 


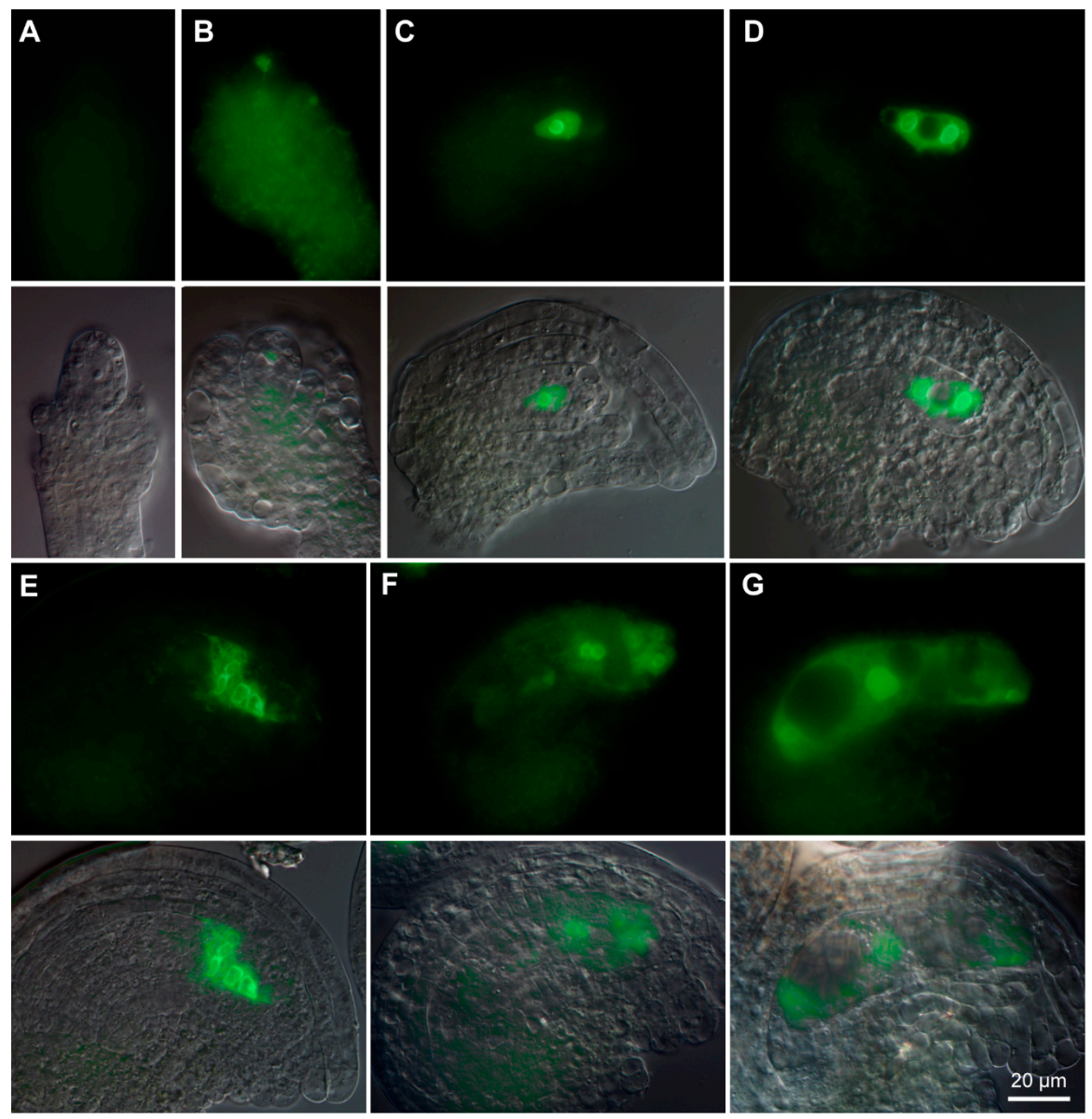

Figure 4. Expression patterns of ProGPR1:GPR1-EGFP during female gametophyte development. (A) Ovule at stage 2-III. No detectable GPR1-EGFP fluorescence at this stage. (B) Ovule at stage 3-I, showing GPR1-EGFP fluorescence in megaspore mother cell. (C-G) Fluorescence was detected in nucleus and cytoplasm of FG1 stage embryo sac (C); FG3 stage embryo sac (D); FG4 stage embryo sac (E); FG6 embryo sac (F); and FG7 embryo sac (G). Figure (A) to (G) shares the same scale bar as shown in $(\mathrm{G})$.

\subsection{Isolation and Phenotypic Characterization of gpr1 Mutant}

To understand the function of Arabidopsis GPR1, we obtained T-DNA insertion mutant gpr1-1 (SALKseq_034266) and Ds transposon insertion mutant gpr1-2 (CSHL_GT24095) (Figure 5A). RT-PCR analyses revealed that no GPR1 transcripts were detectable in the inflorescence of homozygous gpr1-1 and gpr1-2 mutants (Figure 5B). There was no observable difference in vegetative growth between gpr1 mutants and wild-type plants (Supplemental Figure S7). Although GPR1 was strongly expressed during pollen and ovule development (Figures 1-4), gpr1 mutant showed no defect in pollen viability, pollen development, or seed set under standard growth conditions (Supplemental Figures S8 and S9), except for its pollen grains exhibiting a pale yellow color compared with wild type (Figure 6). To elucidate why gpr1 pollen grains exhibited pale color, we examined pollen surface by scanning electron microscopy (SEM) and confocal laser scanning microscope (CLSM). gpr1 pollen grains displayed a normal patterned but thinner exine surface with thinner muri and larger lacunae compared with wild type (Figure 7; Supplemental Figure S10). These results indicate that the gametophyte-specific GPR1 is not required for pollen viability and seed set, but may play roles in post gametogenesis process such as pollen coat formation. 

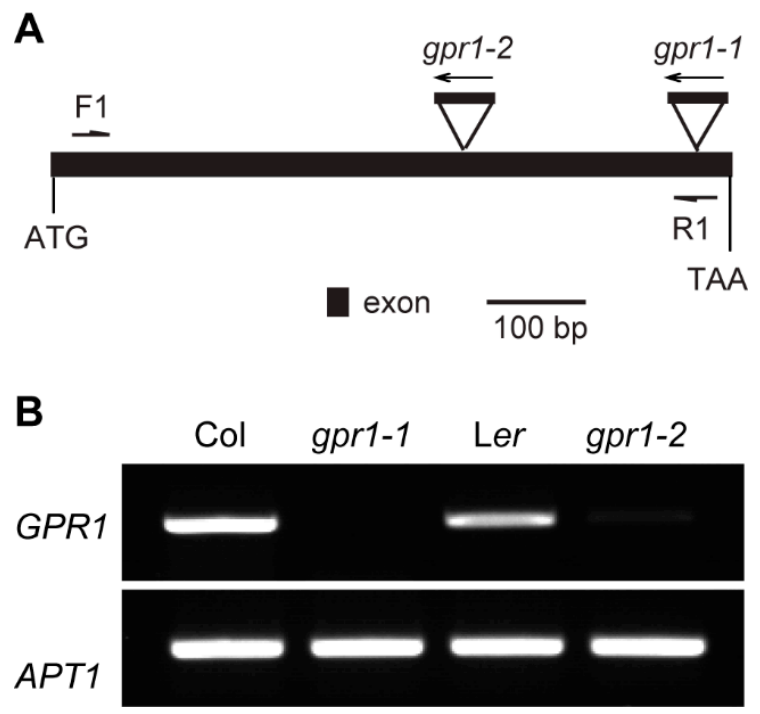

Figure 5. Isolation of gpr1 mutant. (A) Schematic diagram of T-DNA or Ds insertion sites in gpr1 mutants. Dark box indicates exon; triangles indicate T-DNA or Ds insertion sites. (B) Reverse transcription (RT)-PCR analysis of the expression levels of GPR1 in wild-type, gpr1-1, and gpr1-2 flower buds. APT1 was used as the internal control.
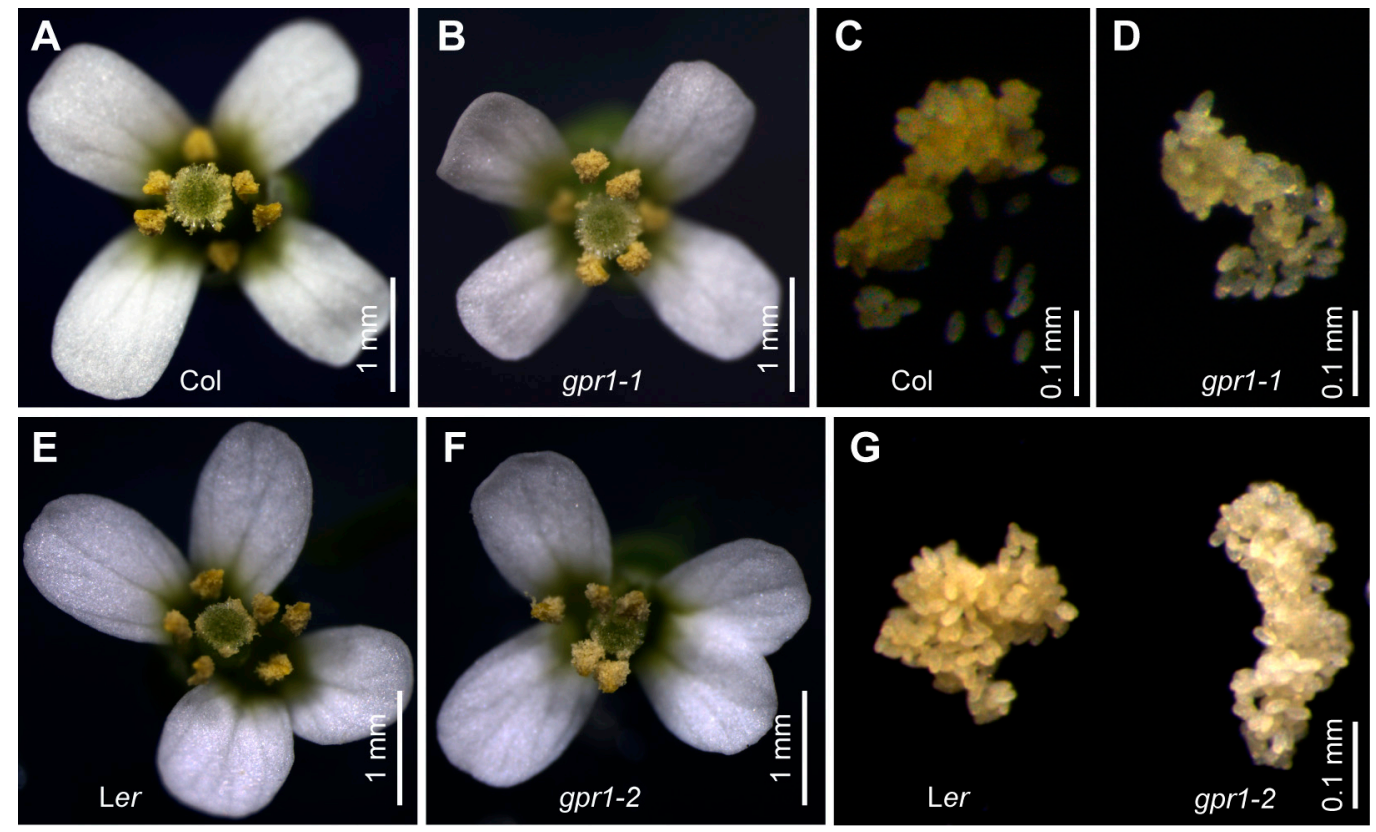

Figure 6. Pollen grains of gpr1 mutants are pale in color. (A,B) Flower from Col wild type and gpr1-1 mutant. (C,D) Pollen grains collected from Col and gpr1-1 mutant. (E,F) Flower from Ler wild type and gpr1-2 mutant. (G) Pollen grains collected from Ler and gpr1-2 mutant. Note pollen grains of gpr1-1 and gpr1-2 are pale compared with those of the wild type. 

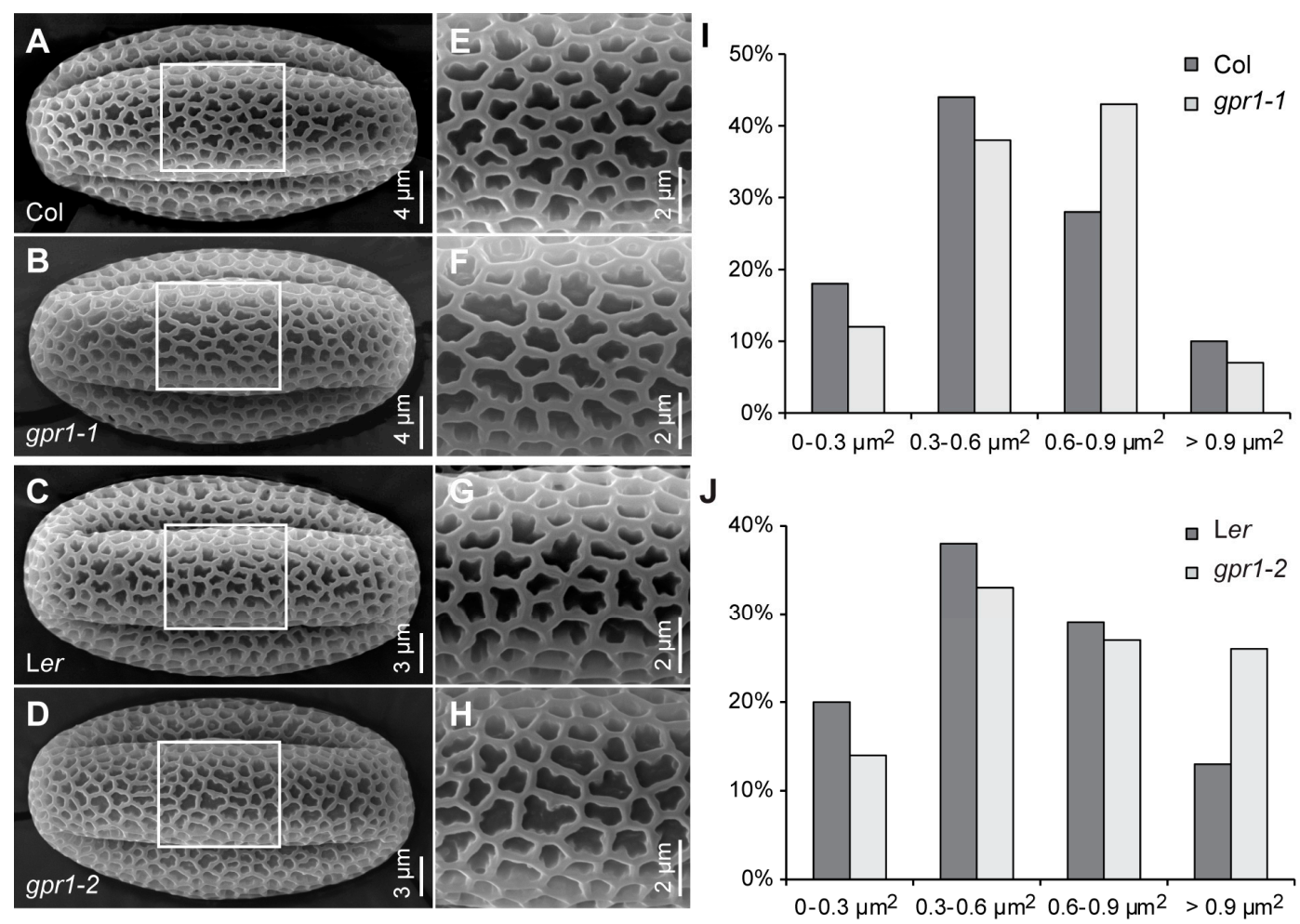

Figure 7. Pollen grain surface of wild-type and gpr1 mutant. (A-H) Scanning electron micrographs of the surface of pollen grains from wild type and gpr1 mutant. (E-H) Higher-magnification images of rectangular regions in (A-D), respectively. (I,J) Lacunae size of pollen grain exine $(n=183-193)$.

\subsection{GPR1 Loss-of-Function Promotes Pollen Germination and Pollen Tube Growth}

To determine whether GPR1 mutation affects post gametogenesis process, we examined pollen germination in in vitro and in vivo environments. When cultured on pollen germination medium for 8 hours, gpr1 pollen germinated as efficiently as wild-type pollen (Supplemental Figure S11A-H). However, gpr1 pollen tubes were significantly longer than that of wild-type (Supplemental Figure S11F,H). To analyze the growth of pollen tubes in vivo, we pollinated wild-type pistils with pollen grains from the gpr 1 mutants or wild-type plant. At $6 \mathrm{~h}$ after pollination (HAP), wild-type (Col and Ler) pollen tubes had just reached the top of the transmitting tract (Supplemental Figure S11I,M). By contrast, gpr1 pollen tubes had penetrated into the upper part of the transmitting tract (Supplemental Figure S11J,N). At 8 HAP, majority of wild-type pollen tubes were still in the upper part of the transmitting tract, only a few pollen tubes turned toward ovules (Supplemental Figure $\mathrm{S} 11 \mathrm{~K}, \mathrm{O}$ ). By contrast, gpr1 pollen tubes reached more than half of the transmitting tract and most pollen tubes grew to entering the ovules (Supplemental Figure S11L,P).

Longer pollen tubes suggesting hyperactive germination or faster growth velocity. To determine the growth dynamics of gpr1 pollen tubes, we germinated pollen grains of wild type and gpr1 plants in vitro for a series of time from 0 to $2 \mathrm{~h}$. Pollen grains of the gpr 1 mutants exhibited hyperactive germination (Figure $8 \mathrm{~A}, \mathrm{~B}$ ). For example, at $0 \mathrm{~h}$, approximately $3 \%$ of gpr $1-1$ and $1 \%$ of gpr $1-2$ pollen grains already exhibited pollen tube protrusion, which was undetectable in wild-type pollen grains ( $n=1233,1239,1286$, and 1946 for Col, gpr1-1, Ler, and gpr1-2, respectively; Figure 8B). At 0.5 h, approximately $8 \%$ of gpr1-1 and $20 \%$ of gpr1-2 pollen grains had germinated ( $n=1036$ for gpr1-1, and 2004 for gpr1-2; Figure 8B). By contrast, only approximately $2 \%$ of Col pollen grains and $1 \%$ of Ler pollen grains germinated ( $n=519$ for Col, and 2108 for Ler; Figure 8B). Although precocious pollen germination was not observed inside the dehiscing gpr1 anthers in the morning (Data not shown), in the afternoon, long pollen tubes can be observed inside dehiscing gpr1 anthers (Figure 8D). 
This phenomenon was not observed in the wild-type anther (Figure 8C). We further recorded the in vitro pollen tube elongation by intervals of $5 \mathrm{~min}$, and quantified its growth rate. The results showed that pollen tubes of the gpr1 mutants elongated faster than those of the wild type (Figure 9).

Taken together, these results indicate that GPR1 functions as a negative regulator of pollen germination and pollen tube growth.

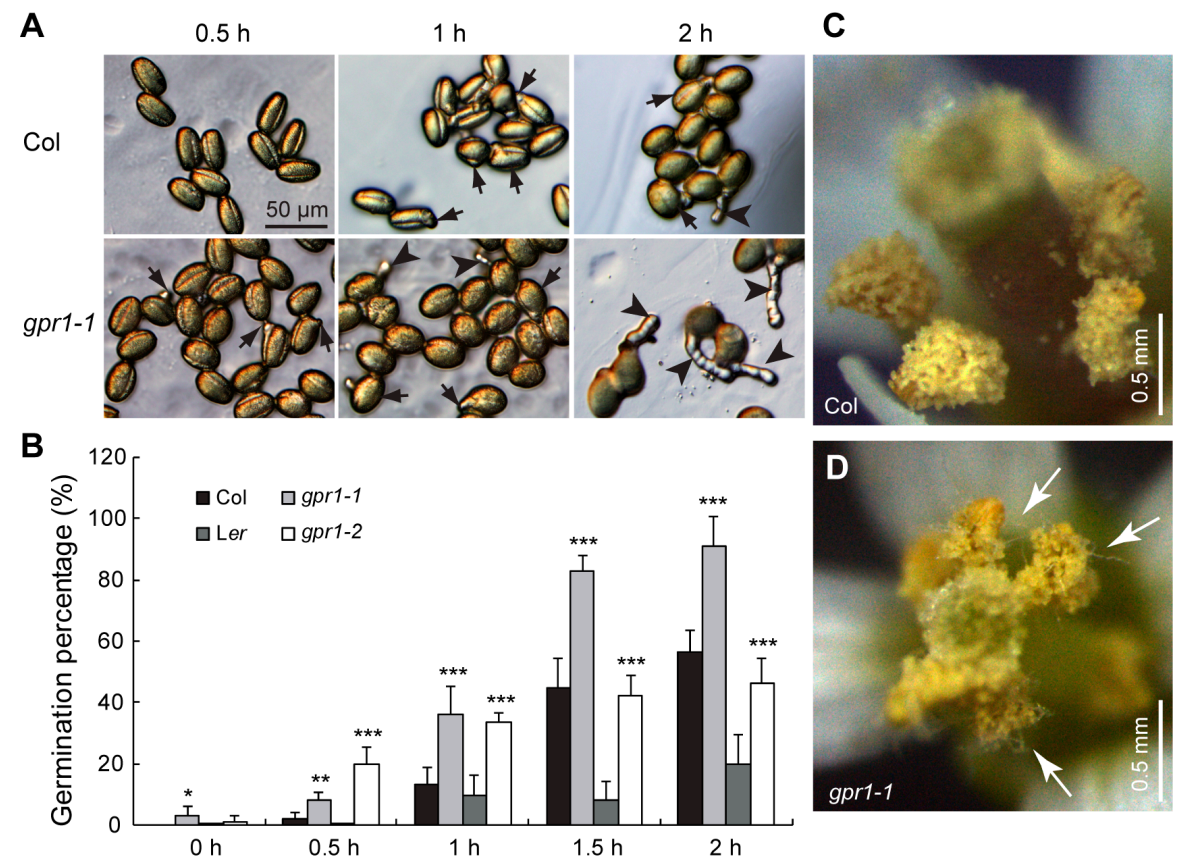

Figure 8. Precocious germination of gpr1 pollen grains. (A) Representative images taken at the indicated time point. Black arrows indicate pollen grains with tube protrusion; black arrowheads indicate pollen grains with tubes equal to or longer than their diameter. (B) Pollen germination rate. The data were presented as the means $\pm \mathrm{SD}\left(n=519-2108 ;^{*} p<0.05,{ }^{* *} p<0.01,{ }^{* * *} p<0.001\right.$ by Student's $t$ test $)$. (C,D) Images of opening flowers of wild type (C) and gpr1-1 (D) taken in the afternoon. White arrows indicate pollen tubes. Note precocious pollen germination inside the gpr1-1 anther.

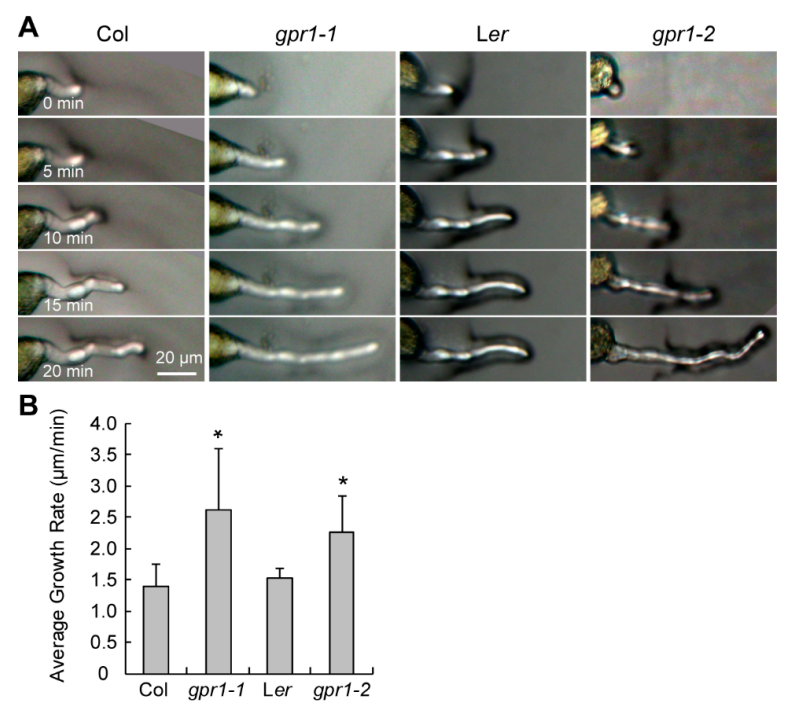

Figure 9. Time-course in vitro pollen germination assay. (A) Representative microscope images taken at 5-min intervals. (B) Mean growth velocity of WT (Col or Ler) and gpr1 mutant pollen tubes. The data were presented as the means $\pm \mathrm{SD}\left(n=34-53 ;{ }^{*} p<0.05\right.$ by Student's $t$ test). 


\subsection{Senescence Marker Expressed Earlier in Unfertilized gpr1 Pistil}

When observing the expressions of ProGPR1:GUS and ProGPR1:GPR1-EGFP, we noticed strong GUS and GPR1-EGFP signals in aborted ovules (Supplemental Figure S12). We then examined the expression of ProGPR1:GUS in unfertilized pistils after emasculation. GUS activity was detected specifically in the embryo sac at 0 day post emasculation (DPE); then GUS signal was observed in the whole ovule at 1 to 3 DPE; at 4 DPE, GUS signal was absent in ovules located in the base of the pistil; at 5 DPE some apical ovules also lost the GUS signal (Supplemental Figure S13). This expression pattern of ProGPR1:GUS in unfertilized pistil is opposite to that of senescence markers like SAG12:GUS and $P_{B F N 1}$ :GUS $[19,20,22]$. To determine whether GPR1 mutation affect ovule senescence, we crossed $P_{B F N 1}$ :GUS (in Col background) into both of the gpr1 mutants and the Ler wild-type plant (to eliminate background influence). Then we examined $P_{B F N 1}$ :GUS expression in unfertilized pistils of wild-type and gpr1 mutants. In unfertilized Ler wild-type pistils, $P_{B F N 1}$ :GUS expression was first observed in the transmitting tract of the 2 DPE pistils; then it was detected in the ovules located in the base of the pistil at 3 DPE; finally, GUS staining was detected in all ovules of pistil at 4 DPE (Figure 10A). Whereas pistil of the gpr1-2 mutant exhibited GUS staining one-day earlier than pistil of the Ler wild type (Figure 10B). Similar trend was observed for gpr1-1 mutant (Data not shown).

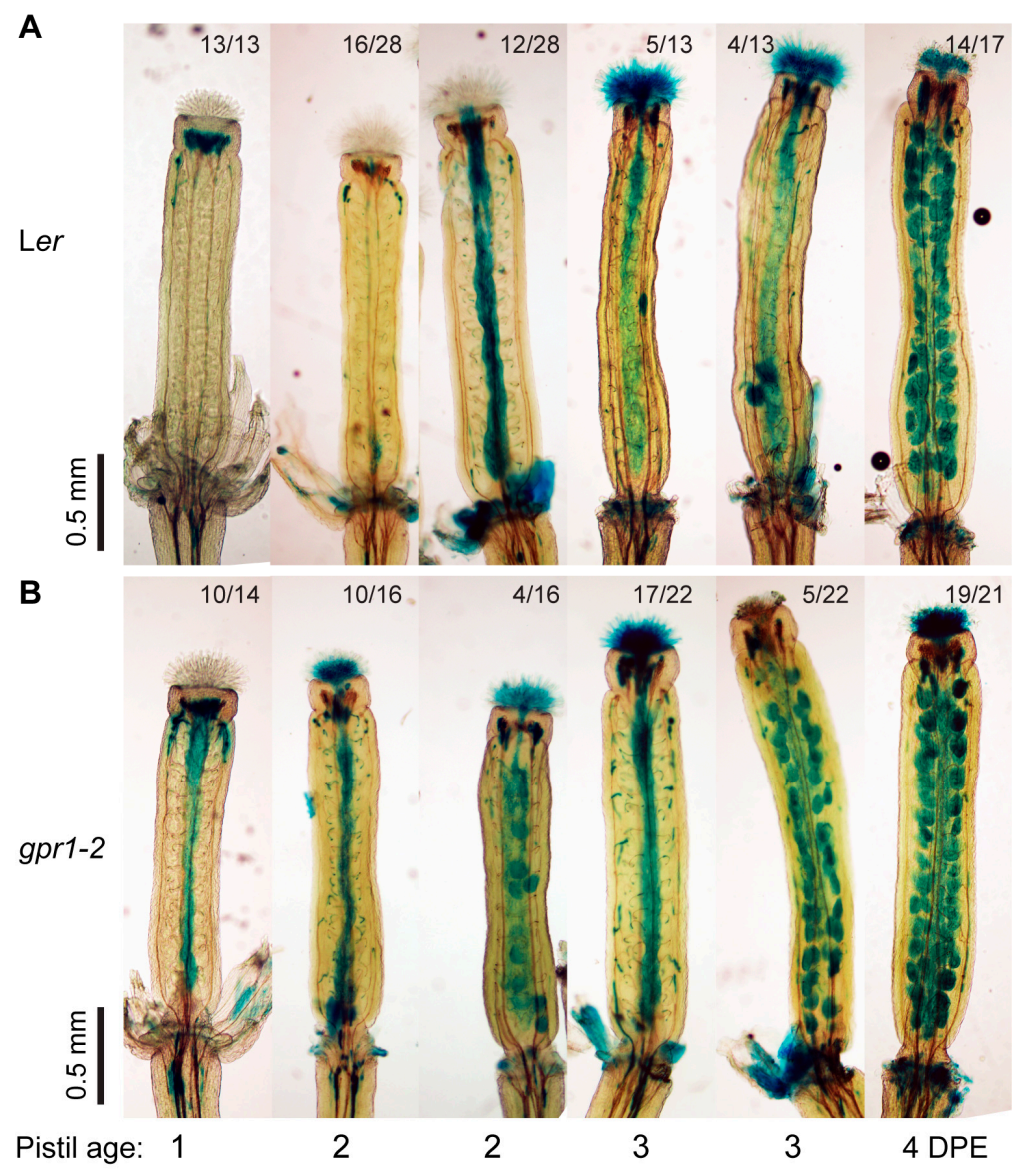

Figure 10. Expression of the senescence marker $P_{B F N 1}$ :GUS in unfertilized wild-type (Ler) and gpr1-2 pistil. (A) GUS staining in unfertilized pistils of the $P_{B F N 1}$ :GUS line crossed into Ler background at 0 to 5 day post emasculation (DPE). (B) GUS staining in unfertilized pistils of the $P_{B F N 1}$ :GUS line in gpr1-2. The number of pistils showing the corresponding GUS expression pattern and total number of pistils examined is indicated above each image. The experiments were repeated three times, shown are the results of one experiment. 


\subsection{GPR1 Mutation Shortens Gametophyte Lifespan}

The above findings suggest that GPR1 may have a role in ovule senescence. To test this, we compared the seed set ability between gpr1 and wild type after emasculation for 1 to 5 days. When pollinated at 1 to $3 \mathrm{DPE}$, wild type and gpr 1 pistils produced comparable number of seeds (Figure 11A,B). However, gpr1 pistils produced significantly less seeds than wild-type pistils when pollinated at 4 to 5 DPE (Figure 11A,B). These results indicate that gpr 1 ovule has a shorter lifespan than that of wild-type plant.

To examine whether GPR1 mutation also affect pollen longevity, we compared the fertilization efficiency of $\operatorname{gpr} 1$ pollen grain with that of wild type after storage at $4{ }^{\circ} \mathrm{C}$ for a series of time of 1 to 5 days. The results showed that pollinations using gpr1 pollen grains produced less seeds than the ones using wild-type pollen grains (Figure 11C,D). After stored for 4 to 5 days, the difference between wild-type and gpr1 pollen grains were significant (Figure 11C,D). These results suggest that gpr1 pollen grains are less viable than that of the wild type after long time storage.

A

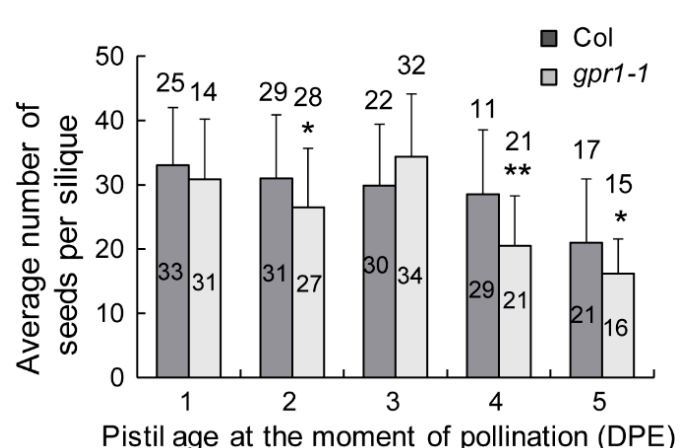

C

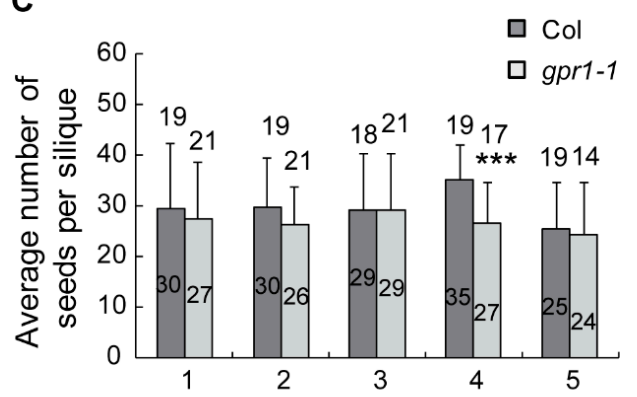

Pollen age at the moment of pollination (DPA)
B

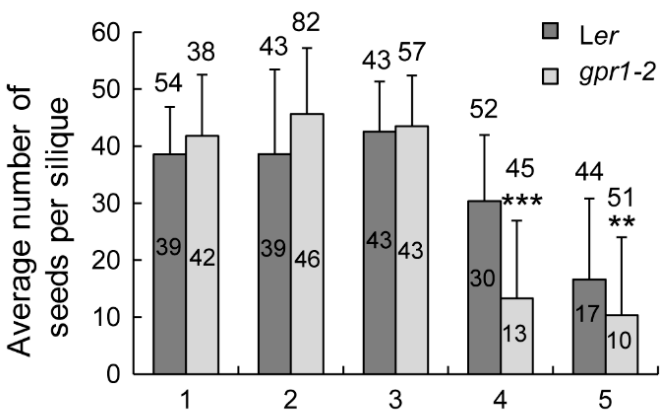

Pistil age at the moment of pollination (DPE)

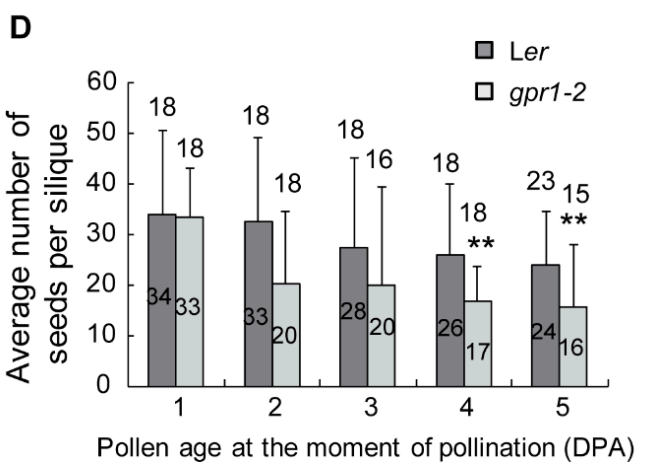

Figure 11. Ovule and pollen lifespan assay. $(\mathbf{A}, \mathbf{B})$ Average seed set of emasculated gpr1 or wild-type pistils 10 days after hand pollination with wild-type pollen grains. (C,D) Average seed set of emasculated wild-type pistils 10 days after hand pollination with gpr1 or wild-type pollen grains. Numbers above the bar indicate total siliques examined; numbers inside the bar represent the average number of seeds per silique. ${ }^{*} p<0.05,{ }^{* *} p<0.01,{ }^{* * *} p<0.001$ by Student's $t$ test.

\section{Discussion}

Flowering plants have evolved a highly elaborated reproduction system, which includes gametophyte development, pollination, and fertilization. All these processes are precisely regulated. To date, many genes essential for these processes have been identified and characterized. However, genes that fine-tune these processes are largely unknown. In this study, we show that GPR1 is specifically expressed in ovule, pollen and pollen tube. GPR1 is not essential for gametogenesis and fertilization, but inhibits hyperactive pollen germination and pollen tube growth, and has positive 
effects on pollen and ovule longevity. Together, these data suggest that GPR1 is required for optimal pollination and fertilization processes.

\subsection{GPR1 Affects Pollen Exine Formation}

Pollen grains of angiosperms have an outer exine layer that protect pollen and interact with pistil stigma [23-26]. Main components of pollen exine are fatty acid derivatives and phenolics [27-29]. A growing number of genes have been identified that are important for pollen exine formation, such as MALE STERILITY2 [30], CYP703A2 and CYP704B2 [31,32]; RUPTURED POLLEN GRAIN1 (RPG1), which are involved in fatty acid metabolism [33]; At5g62080 and At5g07230, genes encoding type III lipid transfer proteins [34]; AtbZIP34, which encodes a bZIP-family transcription factor [35]; AtSEC31B, which encodes a secretory COPII protein [36]. Mutations of these genes usually cause severe pollen exine deposition or patterning defects, and lead to male sterility. Unlike these genes, gpr1 loss-of-function mutant exhibit normal patterned but thinner exine surface (Figure 7; Supplemental Figure S10). This finding indicates that GPR1 do not affect pollen exine deposition or patterning, but controls the thickness of the exine. Consistent with this function, GPR1 is specifically expressed during the period of exine synthesis, and is expressed in tapetal cells, which secrete exine materials to the developing microspores (Figures 1 and 3; Supplemental Figure S3).

\subsection{GPR1 Inhibits Pollen Germination and Pollen Tube Growth}

In order to achieve successful fertilization, pollen germination and pollen tube growth are under stringent regulation. To date, a lot of genes essential for pollen germination and tube growth have been identified, and almost all of these genes are positive regulators. However, negative regulators are required to precisely regulate pollen germination and pollen tube growth. So far only a few genes have been identified as negative regulators of pollen germination. Mutations of these genes lead to premature pollen germination within the anther [4-8]. In an attempt to screen genes that are highly expressed in mature pollen but not required for pollen germination and pollen tube growth, Ju et al. identified the JINGUBANG (JGB) gene [7]. Pollen grains of the $j g b$ loss-of-function mutant exhibited normal germination under standard growth conditions, but exhibited hyperactive germination in moist environments [7]. In this study, we identified GPR1 as a negative regulator of pollen germination and tube growth. Loss of GPR1 function leads to accelerated pollen germination and faster tube growth (Supplemental Figure S11; Figures 8 and 9). These findings suggest that GPR1 is required to maintain the optimal pollen germination and tube growth speed. Pollen grains speed up or slow down the tube growth speed via modulation of the plasma membrane $\mathrm{H}^{+}$ATPase activity [37]. JGB inhibits pollen germination through regulating pollen jasmonic acid (JA) synthesis [7]. However, how GPR1 inhibits pollen germination and tube growth need further investigation.

\subsection{GPR1 Inhibits Ovule and Pollen Senescence}

Ovule and pollen longevity is an important factor in determining the ability to produce seeds. The life span of ovule and pollen is species specific and adapted to its ecological requirements [20,38]. Ethylene has been reported to regulate the onset of ovule senescence [20]. In this study, we found that expression pattern of GPR1 in unfertilized pistils is in contrast to senescence markers SAG12:GUS and $P_{B F N 1}$ :GUS (Supplemental Figure S13) [19,20], suggesting that GPR1 may have a role in ovule senescence. Further emasculation and hand pollination assay showed that loss of GPR1 function shortens both ovule and pollen longevity (Figure 11). Therefore, GPR1 exerts positive effects on ovule and pollen life span.

Although the characterization of the gpr1 mutants provides insights into the role of the ovuleand pollen-specific GPR1 gene, the molecular mechanisms of how it negatively regulates pollen germination and tube growth, and how it promotes the longevity of both ovules and pollen grains remain unknown. Investigation of these questions will provide further insights into the molecular basis that fine tunes pollination and fertilization. 


\section{Materials and Methods}

\subsection{Plant Materials and Growth Conditions}

T-DNA insertion mutant SALKseq_034266 (gpr1-1) is in Col-0 background; and transposon insertion mutant CSHL_GT24095 (gpr1-2) is in Ler background. These mutants were obtained from the Nottingham Arabidopsis Stock Centre (NASC) (Leicestershire, England, UK) and the Cold Spring Harbor Laboratory (CSHL) (Cold Spring Harbor, NY, USA) genetrap collection, respectively. T-DNA or transposon insertion was confirmed by PCR-based genotyping. Primers used are listed in Supplemental Table S1. Plants were cultured under controlled environments at $22 \pm 1{ }^{\circ} \mathrm{C}, 70 \%$ relative humidity with a $16 \mathrm{~h}$ light $/ 8 \mathrm{~h}$ dark photoperiod.

\subsection{Plasmid Construction and Generation of Transgenic Plants}

To create the ProGPR1:GUS construct, 2567 bp sequence upstream of the GPR1 gene start codon were PCR-amplified. The resulting fragment was inserted upstream of the GUS reporter gene in the pGreenII0229-GUS vector via XhoI and SpeI sites [39]. Then, 419 bp of sequence downstream the GPR1 stop codon ( $3^{\prime}$ regulating sequence of the GPR1 gene) was amplified and cloned into the vector downstream of the GUS gene. To generate the ProGPR1:GPR1-EGFP translational fusion construct, the GPR1 promoter and full-length coding sequence (nucleotides - 2567 to 690 from ATG) was amplified and inserted into the pGreenII0229-EGFP plasmid in frame with the EGFP gene [40]. Then, the $3^{\prime}$ regulating sequence of the GPR1 gene (419 bp) was cloned into the above constructed vector at downstream of the EGFP gene. To generate the ProLAT52:GPR1-EGFP construct, the 666 bp promoter fragment of the LAT52 gene was amplified from Solanum lycopersicum and cloned into the pGreenII0229-GPR1-EGFP vector upstream of the GPR1 coding sequence. To construct the p35S:EGFP-GPR1 plasmid, the EGFP fragment was cut from the pGreenII0229-EGFP plasmid using XhoI and SacI enzymes, then inserted into the pBA002 vector (with CaMV 35S promoter; from Nam-Hai Chua) using the same sites; then GPR1 full-length cDNA was cloned into the pBA002-EGFP vector at downstream of the EGFP gene and in frame with EGFP.

All constructed vectors were introduced into Agrobacterium tumefaciens strain C58C1 (pMP90/pJIC Sa-Rep) and transformed into wild-type Arabidopsis (Col-0) plants by floral dip method [41]. Seeds harvested from the transformed plants were sowed in soil and screened by spraying $10 \mathrm{mg} \mathrm{L}^{-1}$ Basta (Sangon Biotech, Shanghai, China). Basta resistant plants were verified by PCR. Homozygous lines (T3 generation) were obtained from several independent transformants to perform analyses. All primers used are listed in Supplemental Table S1.

\subsection{RT-PCR Analysis}

RT-PCR was performed to test the transcription levels of the GPR1 gene in mutant or wild-type plants. Total RNA was extracted from inflorescences of 5-week-old plants using Trizol reagent. The first-strand cDNA was synthesized using EasyScript First-Strand cDNA Synthesis SuperMix (TransGen Biotech, Beijing, China). The APT1 gene was used as an internal control for equal loading. The primer sequences are listed in Supplemental Table S1.

\subsection{GUS Histochemical Staining}

For GUS staining, various tissues of ProGPR1:GUS transgenic plants were incubated for $12 \mathrm{~h}$ at $37^{\circ} \mathrm{C}$ in GUS staining buffer as previously described [40]. After staining, the tissue was cleared in chloral hydrate:distilled water:glycerol (8:3:1, w:v:v). Inflorescences were examined using a Leica M165FC stereomicroscope. Developing ovules were dissected and observed under an Olympus BX63 microscope using differential interference contrast (DIC) optics. Ovule developmental stages were determined as described previously [42]. 


\subsection{Scanning Electron Microscopy and Fluorescence Microscopy}

For scanning electron microscopy, flowers from wild-type, gpr1-1 and gpr1-2 plants were dissected; pollen grains were subjected to freeze drying, then mounted for coating with gold and observed on a QUANTA 200 (FEI, Hillsboro, OR, USA) scanning electron microscope. For observation expression pattern of GPR1-EGFP in ovules and anthers, flowers were dissected at different developmental stages and mounted in an $8 \%$ glycerol solution. Fluorescent signals were detected by confocal laser scanning microscope (CLSM, Leica TCS SP5, Wetzlar, Germany).

\subsection{Pollen Grain and Pollen Tube Staining}

To assay pollen viability, Alexander staining was carried out as described [43], and then cleared in Herr's solution [44] for $2 \mathrm{~h}$. For DAPI and callose staining, flowers were fixed in ethanol:acetic acid (3:1) solution for $2 \mathrm{~h}$, and treated with $2 \mathrm{~N} \mathrm{NaOH}$ for $10 \mathrm{~min}$. After washing with $50 \mathrm{mmol} \cdot \mathrm{L}^{-1}$ $\mathrm{K}_{2} \mathrm{HPO}_{4}-\mathrm{KOH}$ buffer ( $\mathrm{pH}$ 7.5) for three times, pollen grains were immersed with $1 \mathrm{~g} \cdot \mathrm{L}^{-1} \mathrm{DAPI}$ (Sigma-Aldrich, Steinheim, Germany) for staining DNA. The stained nuclei were detected using a Leica DM2500 microscope (Leica, Wetzlar, Germany) with a UV filter.

To visualize the in vivo geminated pollen tubes, aniline blue staining was performed as described previously [45]. Emasculated wild-type flowers were pollinated either with wild type or gpr1 pollen grains. Six or eight hour after pollination, the pistils were fixed in acetic acid:chloroform:ethanol (1:3:6) for $2 \mathrm{~h}$. Then, the pistils were washed in distilled $\mathrm{H}_{2} \mathrm{O}$, and softened overnight in $8 \mathrm{~N} \mathrm{NaOH}$. After the softening step, the pistils were washed three times with distilled $\mathrm{H}_{2} \mathrm{O}$, and then stained with aniline blue solution $\left(0.05 \%\right.$ aniline blue in $0.1 \mathrm{~mol} \cdot \mathrm{L}^{-1}$ potassium phosphate buffer, $\left.\mathrm{pH} 7.5\right)$ for $3 \mathrm{~h}$ by avoiding light. After staining, pistils were washed with $0.1 \mathrm{~mol} \cdot \mathrm{L}^{-1}$ potassium phosphate buffer, and mounted on a microscope slide, and gently squashed under a cover slip. The pistils were observed using a Leica DM2500 microscope with a UV filter.

\subsection{In Vitro Pollen Germination Analysis}

In vitro pollen germination was performed according to previously published methods [46]. Briefly, pollen grains collected from newly opened flowers were placed on pollen germination medium [1 mmol $\cdot \mathrm{L}^{-1} \mathrm{CaCl}_{2}, 1 \mathrm{mmol} \cdot \mathrm{L}^{-1} \mathrm{Ca}\left(\mathrm{NO}_{3}\right)_{2}, 1 \mathrm{mmol} \cdot \mathrm{L}^{-1} \mathrm{MgSO}_{4}, 0.01 \%(w / v) \mathrm{H}_{3} \mathrm{BO}_{3}$, and $18 \%$ $(w / v)$ sucrose, solidified with $0.5 \%(w / v)$ agar, $\mathrm{pH} 7.0]$. The plates were cultured at $28{ }^{\circ} \mathrm{C}$ under moist conditions. After $8 \mathrm{~h}$ incubation, digital images were collected with a Leica DFC420 CCD camera equipped on a Leica M165FC stereomicroscope (Leica, Wetzlar, Germany). Pollen germination percentage and the length of the pollen tubes were measured using ImageJ software. Protrusion from the aperture was regarded as positive germination [47].

\subsection{Female and Male Gametophytes Longevity Test}

To test the longevity of ovules, flowers one day before anthesis from gpr1 mutant and wild type were emasculated, then the pistils were hand pollinated with freshly harvested wild-type pollen grains at 1 to 5 days post emasculation. Ten days after pollination, siliques were harvested and seeds were counted. For pollen lifespan analysis, mature pollen grains were harvested from opening flowers of gpr1 mutants and wild type, and were stored at $4{ }^{\circ} \mathrm{C}$ for 1 to 5 days before pollinated to pistils of freshly emasculated wild type flowers. Ten days after pollination, siliques were harvested and seeds were counted.

Supplementary Materials: Supplementary materials can be found at www.mdpi.com/1422-0067/18/6/1303/s1.

Acknowledgments: This work was supported by grants from the National Natural Science Foundation of China (31570247, 91417308 and 31460453); the Natural Science Foundation of Tianjin (No. 14JCYBJC41200). We thank Miguel A. Perez-Amador and Amnon Lers for the $P_{B F N 1}$ :GUS seeds; the Nottingham Arabidopsis Stock Centre (NASC) and the Cold Spring Harbor Laboratory (CHSL) for the T-DNA or transposon insertions; John Innes Centre for the pGREENII0229 vector; Nam-Hai Chua for the pBA002 vector. We thank Ruming Liu and Di An for technical assistance in the use of confocal and scanning electron microscope, respectively. 
Author Contributions: Shuzhen Men conceived the project and designed experiments. Xiao Yang performed most of the experiments, and drafted a manuscript; Qinying Zhang performed $P_{\mathrm{BFN} 1}$ :GUS expression analysis and the ovule and pollen lifespan assay, and analyzed the expression of ProGPR1:GUS in unfertilized pistils; Kun Zhao did the measurements of the pollen surface lacuna size and pollen tube length; Qiong Luo performed $P_{\mathrm{BFN} 1}$ :GUS expression analysis and the ovule and pollen lifespan assay; Shuguang Bao performed scanning electron microscopy of pollen grains and analyzed the expression of ProGPR1:GUS in unfertilized pistils; Huabin Liu helped with GPR1-EGFP localization analysis. Shuzhen Men analyzed the data and wrote the manuscript.

Conflicts of Interest: The authors declare no conflict of interest. The founding sponsors had no role in the design of the study; in the collection, analyses, or interpretation of data; in the writing of the manuscript, and in the decision to publish the results.
Abbreviations
DPA Day post anthesis
DPE Day post emasculation
Hag Hour after germination
Hap Hour after pollination

\section{References}

1. Heslop-Harrison, J. An interpretation of the hydrodynamics of pollen. Am. J. Bot. 1979, 66, 737-743. [CrossRef]

2. Taylor, L.P.; Hepler, P.K. Pollen germination and tube growth. Annu. Rev. Plant Physiol. Plant Mol. Biol. 1997, 48, 461-491. [CrossRef] [PubMed]

3. Sanchez, A.M.; Bosch, M.; Bots, M.; Nieuwland, J.; Feron, R.; Mariani, C. Pistil factors controlling pollination. Plant Cell 2004, 16, S98-S106. [CrossRef] [PubMed]

4. Johnson, S.A.; McCormick, S. Pollen germinates precociously in the anthers of raring-to-go, an Arabidopsis gametophytic mutant. Plant Physiol. 2001, 126, 685-695. [CrossRef] [PubMed]

5. Xie, B.; Wang, X.; Hong, Z. Precocious pollen germination in Arabidopsis plants with altered callose deposition during microsporogenesis. Planta 2010, 231, 809-823. [CrossRef] [PubMed]

6. Wang, Y.; Chu, Y.J.; Xue, H.W. Inositol polyphosphate 5-phosphatase-controlled Ins $(1,4,5) P 3 / \mathrm{Ca}^{2+}$ is crucial for maintaining pollen dormancy and regulating early germination of pollen. Development 2012, 139, 2221-2233. [CrossRef] [PubMed]

7. Ju, Y.; Guo, L.; Cai, Q.; Ma, F.; Zhu, Q.Y.; Zhang, Q.; Sodmergen, S. Arabidopsis JINGUBANG is a negative regulator of pollen germination that prevents pollination in moist environments. Plant Cell 2016, 28, 2131-2146. [CrossRef] [PubMed]

8. Cheung, A.Y.; Wang, H.; Wu, H.M. A floral transmitting tissue-specific glycoprotein attracts pollen tubes and stimulates their growth. Cell 1995, 82, 383-393. [CrossRef]

9. Hülskamp, M.; Schneitz, K.; Pruitt, R.E. Genetic evidence for a long range activity that directs pollen tube guidance in Arabidopsis thaliana. Plant Cell 1995, 7, 57-64. [CrossRef] [PubMed]

10. Okuda, S.; Tsutsui, H.; Shiina, K.; Sprunck, S.; Takeuchi, H.; Yui, R.; Kasahara, R.D.; Hamamura, Y.; Mizukami, A.; Susaki, D.; et al. Defensin-like polypeptide LUREs are pollen tube attractants secreted from synergid cells. Nature 2009, 458, 357-361. [CrossRef] [PubMed]

11. Qu, L.J.; Li, L.; Lan, Z.J.; Dresselhaus, T. Peptide signalling during the pollen tube journey and double fertilization. J. Exp. Bot. 2015, 66, 5139-5150. [CrossRef] [PubMed]

12. Steinhorst, L.; Kudla, J. Calcium-A central regulator of pollen germination and tube growth. Biochim. Biophys. Acta 2013, 1833, 1573-1581. [CrossRef] [PubMed]

13. Krichevsky, A.; Kozlovsky, S.V.; Tian, G.W.; Chen, M.H.; Zaltsman, A.; Citovsky, V. How pollen tubes grow. Dev. Biol. 2007, 303, 405-420. [CrossRef] [PubMed]

14. Cole, R.A.; Fowler, J.E. Polarized growth: Maintaining focus on the tip. Curr. Opin. Cell Biol. 2006, 9, 579-588. [CrossRef] [PubMed]

15. Obermeyer, G.; Weisenseel, M.H. Calcium channel blocker and calmodulin antagonists affect the gradient of free calcium ions in lily pollen tubes. Eur. J. Cell Biol. 1991, 56, 319-327. [PubMed]

16. Cheung, A.Y.; Wu, H.M. Structural and signaling networks for the polar cell growth machinery in pollen tubes. Annu. Rev. Plant Biol. 2008, 59, 547-572. [CrossRef] [PubMed] 
17. Wang, H.J.; Wan, A.R.; Jauh, G.Y. An actin-binding protein, L1LIM1, mediates calcium and hydrogen regulation of actin dynamics in pollen tubes. Plant Physiol. 2008, 147, 1619-1636. [CrossRef] [PubMed]

18. Zhang, H.; Qu, X.L.; Bao, C.C.; Khurana, P.; Wang, Q.N.; Xie, Y.R.; Zheng, Y.Y.; Chen, N.Z.; Blanchoin, L.; Staiger, C.J.; et al. Arabidopsis VILLIN5, an actin filament bundling and severing protein, is necessary for normal pollen tube growth. Plant Cell 2010, 22, 2749-2767. [CrossRef] [PubMed]

19. Carbonell-Bejerano, P.; Urbez, C.; Carbonell, J.; Granell, A.; Perez-Amador, M.A. A fertilization-independent developmental program triggers partial fruit development and senescence processes in pistils of Arabidopsis. Plant Physiol. 2010, 154, 163-172. [CrossRef] [PubMed]

20. Cabonell-Bejerano, P.; Urbez, C.; Granell, A.; Carbonell, J.; Perez-Amador, M.A. Ethylene is involved in pistil fate by modulating the onset of ovule senescence and the GA-mediated fruit set in Arabidopsis. BMC Plant Biol. 2011, 11, 84. [CrossRef]

21. Xu, H.P.; Weterings, K.; Vriezen, W.; Feron, R.; Xue, Y.B.; Derksen, J.; Mariani, C. Isolation and characterization of male-germ-cell transcripts in Nicotiana tabacum. Sex. Plant Reprod. 2002, 14, 339-346. [CrossRef]

22. Farage-Barhom, S.; Burd, S.; Sonego, L.; Perl-Treves, R.; Lers, A. Expression analysis of the BFN1 nuclease gene promoter during senescence, abscission, and programmed cell death-related processes. J. Exp. Bot. 2008, 59, 3247-3258. [CrossRef] [PubMed]

23. Heslop-Harrison, J. Wall pattern formation in angiosperm microsporogenesis. Symp. Soc. Exp. Biol. 1971, 25, 277-300. [PubMed]

24. Piffanelli, P.; Ross, J.H.E.; Murphy, D.J. Biogenesis and function of the lipidic structures of pollen grains. Sex. Plant Reprod. 1998, 11, 65-80. [CrossRef]

25. Zinkl, G.M.; Zwiebel, B.I.; Grier, D.G.; Preuss, D. Pollen-stigma adhesion in Arabidopsis: A species-specific interaction mediated by lipophilic molecules in the pollen exine. Development 1999, 126, 5431-5440. [PubMed]

26. Edlund, A.F.; Swanson, R.; Preuss, D. Pollen and stigma structure and function: The role of diversity in pollination. Plant Cell 2004, 16, S84-S97. [CrossRef] [PubMed]

27. Guilford, W.J.; Schneider, D.M.; Labovitz, J.; Opella, S.J. High resolution solid state ${ }^{13}$ C NMR spectroscopy of sporopollenins from different plant taxa. Plant Physiol. 1988, 86, 134-136. [CrossRef] [PubMed]

28. Ahlers, F.; Thom, I.; Lambert, J.; Kuckuk, R.; Wiermann, R. ${ }^{1} \mathrm{H}$ NMR analysis of sporopollenin from Typha angustifolia. Phytochemistry 1999, 50, 1095-1098. [CrossRef]

29. Shi, J.; Tan, H.X.; Yu, X.H.; Liang, W.; Ranathunge, K.; Franke, R.B.; Schreiber, L.; Wang, Y.; Kai, G.; Shanklin, J.; et al. Defective Pollen Wall is required for anther and microspore development in rice and encodes a fatty acyl carrier protein reductase. Plant Cell 2011, 23, 2225-2246. [CrossRef] [PubMed]

30. Aarts, M.G.; Hodge, R.; Kalantidis, K.; Florack, D.; Wilson, Z.A.; Mulligan, B.J.; Stiekema, W.J.; Scott, R.; Pereira, A. The Arabidopsis MALE STERILITY 2 protein shares similarity with reductases in elongation/condensation complexes. Plant J. 1997, 12, 615-623. [CrossRef] [PubMed]

31. Morant, M.; Jorgensen, K.; Schaller, H.; Pinot, F.; Møller, B.L.; Werck-Reichhart, D.; Bak, S. CYP703 is an ancient cytochrome P450 in land plants catalyzing in-chain hydroxylation of lauric acid to provide building blocks for sporopollenin synthesis in pollen. Plant Cell 2007, 19, 1473-1487. [CrossRef] [PubMed]

32. Dobritsa, A.A.; Shrestha, J.; Morant, M.; Pinot, F.; Matsuno, M.; Swanson, R.; Møller, B.L.; Preuss, D. CYP704B1 is a long-chain fatty acid omega-hydroxylase essential for sporopollenin synthesis in pollen of Arabidopsis. Plant Physiol. 2009, 151, 574-589. [CrossRef] [PubMed]

33. Guan, Y.F.; Huang, X.Y.; Zhu, J.; Gao, J.F.; Zhang, H.X.; Yang, Z.N. RUPTURED POLLEN GRAIN1, a member of the MtN3/saliva gene family, is crucial for exine pattern formation and cell integrity of microspores in Arabidopsis. Plant Physiol. 2008, 147, 852-863. [CrossRef] [PubMed]

34. Huang, M.D.; Chen, T.L.; Huang, A.H. Abundant type III lipid transfer proteins in Arabidopsis tapetum are secreted to the locule and become a constituent of the pollen exine. Plant Physiol. 2013, 163, 1218-1229. [CrossRef] [PubMed]

35. Gibalová, A.; Renák, D.; Matczuk, K.; Dupl'áková, N.; Cháb, D.; Twell, D.; Honys, D. AtbZIP34 is required for Arabidopsis pollen wall patterning and the control of several metabolic pathways in developing pollen. Plant Mol. Biol. 2009, 70, 581-601. [CrossRef] [PubMed]

36. Zhao, B.C.; Shi, H.D.; Wang, W.L.; Liu, X.Y.; Gao, H.; Wang, X.X.; Zhang, Y.H.; Yang, M.D.; Li, R.; Guo, Y. Secretory COPII protein SEC31B is required for pollen wall development. Plant Physiol. 2016, 172, 1625-1642. [CrossRef] [PubMed] 
37. Lang, V.; Pertl-Obermeyer, H.; Safiarian, M.J.; Obermeyer, G. Pump up the volume-A central role for the plasma membrane $\mathrm{H}^{+}$pump in pollen germination and tube growth. Protoplasma 2014, 251, 477-488. [CrossRef] [PubMed]

38. Marks, T.R.; Seaton, P.T.; Pritchard, H.W. Desiccation tolerance, longevity and seed-siring ability of entomophilous pollen from UK native orchid species. Ann. Bot. 2014, 114, 561-569. [CrossRef] [PubMed]

39. Men, S.Z.; Boutte, Y.; Ikeda, Y.; Li, X.G.; Palme, K.; Stierhof, Y.D.; Hartmann, M.A.; Moritz, T.; Grebe, M. Sterol-dependent endocytosis mediates post-cytokinetic acquisition of PIN2 auxin efflux carrier polarity. Nat. Cell Biol. 2008, 10, 237-244. [CrossRef] [PubMed]

40. Zhang, X.; Sun, S.L.; Nie, X.; Boutte, Y.; Grison, M.; Li, P.P.; Kuang, S.S.; Men, S.Z. Sterol methyl oxidases affect embryo development via auxin-associated mechanisms. Plant Physiol. 2016, 171, 468-482. [CrossRef] [PubMed]

41. Clough, S.J.; Bent, A.F. Floral dip: A simplified method for Agrobacterium-mediated transformation of Arabidopsis thaliana. Plant J. 1998, 16, 735-743. [CrossRef] [PubMed]

42. Schneitz, K.; Hulskamp, M.; Pruitt, R.E. Wild-type ovule development in Arabidopsis thaliana: A light microscope study of cleared whole-mount tissue. Plant J. 1995, 7, 731-749. [CrossRef]

43. Alexander, M.P. Differential staining of aborted and nonaborted pollen. Stain Technol. 1969, 44, 117-222. [CrossRef] [PubMed]

44. Herr, J.M. A new clearing-squash technique for the study of ovule development in angiosperms. Am. J. Bot. 1971, 58, 785-790. [CrossRef]

45. Ishiguro, S.; Kawai-Oda, A.; Ueda, J.; Nishida, I.; Okada, K. The DEFECTIVE IN ANTHER DEHISCIENCE gene encodes a novel phospholipase A1 catalyzing the initial step of jasmonic acid biosynthesis, which synchronizes pollen maturation, anther dehiscence, and flower opening in Arabidopsis. Plant Cell 2001, 13, 2191-2209. [CrossRef] [PubMed]

46. Ye, J.R.; Zheng, Y.Y.; Yan, A.; Chen, N.Z.; Wang, Z.K.; Huang, S.J.; Yang, Z.B. Arabidopsis formin3 directs the formation of actin cables and polarized growth in pollen tubes. Plant Cell 2009, 21, 3868-3884. [CrossRef] [PubMed]

47. Gibbon, B.C.; Kovar, D.R.; Staiger, C.J. Latrunculin B has different effects on pollen germination and tube growth. Plant Cell 1999, 11, 2349-2363. [CrossRef] [PubMed]

(C) 2017 by the authors. Licensee MDPI, Basel, Switzerland. This article is an open access article distributed under the terms and conditions of the Creative Commons Attribution (CC BY) license (http:/ / creativecommons.org/licenses/by/4.0/). 